\title{
Knowledge, Attitudes, and Likelihood of Pre-Exposure Prophylaxis (PrEP) Use Among US Women at Risk of Acquiring HIV
}

\author{
Judith D. Auerbach, $\mathrm{PhD},{ }^{1}$ Suzanne Kinsky, $\mathrm{MPH}^{2},{ }^{\mathrm{G}}$ Gina Brown, MSW, ${ }^{3}$ and Vignetta Charles, $\mathrm{PhD}^{4}$
}

\begin{abstract}
Although the Food and Drug Administration (FDA) approved oral Truvada for pre-exposure prophylaxis (PrEP) for women at risk of HIV infection in the US in July 2012, and the Centers for Disease Control and Prevention (CDC) issued guidance for clinicians to provide PrEP to women "at substantial risk of HIV acquisition" in May 2014, there remain no clinical trial data on efficacy among US women, and there is a dearth of research on knowledge, attitudes, and likelihood of use of PrEP among them. We conducted a qualitative focus group (FG) study with 144 at-risk women in six US cities between July and September 2013, including locations in the Southern US, where HIV infections among women are most prevalent. FG questions elicited awareness of PrEP, attitudes about administration and uptake, and barriers to and facilitators of use. Women expressed anger at the fact that they had not heard of PrEP prior to the study, but once informed most found it attractive. PrEP was seen as additional, not substitute protection to condoms, and participants suggested several dissemination strategies to meet the diverse needs of women. Key barriers to PrEP uptake included distrust of the medical system, stigma, and cost. Findings suggest that US women view PrEP as an important prevention option, assuming side effects and the cost to the consumer are minimal, the efficacy of the drug is reasonable, and PrEP is delivered by trusted providers in trusted venues.
\end{abstract}

\section{Introduction}

A PPROXIMATELY ONE-QUARTER OF ALL PEOPLE living with HIV in the US are women, ${ }^{1,2}$ and women accounted for $20 \%$ of new HIV infections ${ }^{2}$ and $25 \%$ of new AIDS diagnoses in $2011 .^{3}$ The vast majority (84\%) of HIV infections among women are attributed to heterosexual sex. ${ }^{4}$ Although the overall rate of new infections among women in the US has declined, ${ }^{4}$ there exist significant racial and ethnic disparities. Black women account for nearly two-thirds $(64 \%)$ of new infections among women, though they represent only $13 \%$ of the American population. ${ }^{5}$ In 2010, the rate of new infections among black/African American women was 20 times that of white women and the rate among Hispanic/Latina women was 4 times that of white women. ${ }^{4}$ Young women, including those of reproductive age, are significantly affected: nearly one-third of new infections (29\%) among women occur among those aged 25-44, and $22 \%$ among women aged $13-24 .^{2}$
As HIV transmission continues to occur among women, it is imperative to make effective HIV prevention strategies available to them-particularly those that women can control (unlike the use of male condoms, for example). One such strategy that has received increased attention in recent years is oral pre-exposure prophylaxis (PrEP) with antiretroviral drugs. PrEP has demonstrated efficacy in three randomized clinical trials conducted mostly outside the US involving gay men, serodiscordant couples, and heterosexual men and women; ${ }^{6-8}$ but two studies involving only women were not able to demonstrate efficacy. ${ }^{9,10}$ Although the Food and Drug Administration (FDA) approved oral Truvada (emtricitabine/ tenofovir disoproxil fumarate) for PrEP for at-risk women in the US in July 2012, ${ }^{11}$ and the Centers for Disease Control and Prevention (CDC) issued guidance for clinicians to provide PrEP to women "at substantial risk of HIV acquisition"' in May 2014, ${ }^{12}$ there remain no clinical trial data on efficacy among US women. There is a dearth of research on knowledge, attitudes, and likelihood of use of PrEP among

\footnotetext{
${ }^{1}$ Department of Medicine, University of California San Francisco, San Francisco, California.

${ }^{2}$ Department of Behavioral and Community Health Science, University of Pittsburgh, Pittsburgh, Pennsylvania.

${ }^{3}$ Positive Women's Network-USA, Metaire, Louisiana.

${ }^{4}$ AIDS United, Washington, District of Columbia.
} 
women in the US. ${ }^{13}$ Thus PrEP's potential as an HIV prevention strategy for American women is unknown. The aim of this article is to investigate PrEP's acceptability and feasibility among women at risk for HIV in the US.

\section{Methods}

\section{Overview}

The authors partnered with community-based organizations (CBO) to conduct a formative, qualitative, focus group project with HIV-negative women (operationalized as those who have been tested and know they are HIV negative and those who have not been tested, but who believe they are HIV negative) in six US cities: New York, Dallas, Atlanta, Newark, Chicago, and New Orleans. Given the disparate burden of disease (including among women) in the Southern US, we deliberately located half of the focus groups in the South. Two focus groups were held in each city between July and September 2013. We explicitly aimed to recruit black/ African American women, given their disproportionate risk of HIV in the US. Women were recruited by local womenserving CBOs-SisterLove (Atlanta), AIDS Foundation of Chicago, Afiya Center (Dallas), Hyacinth (Newark), Women With a Vision (New Orleans), and Iris House (New York) that had access and ability to reach the demographic of women desired for this study. Recruitment strategies included: posting flyers at apartment buildings; recruiting at an HIV testing van, homeless shelter and CBO common area; posting on Facebook; word of mouth at CBOs, homeless shelters, and substance abuse outpatient clinics; and outreach at churches. The focus groups were comprised of 10 to 16 women, and were led by trained, local facilitators and conducted at the CBOs. Each session lasted about 90 min. Participants received a $\$ 50$ incentive, which was provided as AmEx gift card distributed at the end of the focus group meeting. Food also was provided to all groups. All participants signed informed consent forms before the sessions began; and the focus groups complied with the ethics requirements for program participation of each host organization.

Because PrEP is a new concept in the HIV/AIDS arena, we chose the focus group method as a way to develop understanding not just about what women potentially at risk of HIV knew and thought about it, but also why they felt the way they did, to better assess the likelihood of their use of PrEP. As a form of informal interviewing, focus groups allow us to examine the ways in which people, in conjunction with others, develop knowledge and construe meanings that might affect their actions. ${ }^{14}$ Moreover, we believed that engaging individuals and organizations with strong community ties in a conversation in a comfortable venue would facilitate more open discussion than would occur in a formal research setting. ${ }^{15}$

\section{Focus group procedures}

At the beginning of each focus group session, participants completed a questionnaire with demographic information. Then the facilitator provided basic information about what PrEP (specifically oral Truvada) is, how it is administered and functions in the body, what side effects have been observed, and what clinical trial data have shown with respect to its efficacy in different populations. A fact sheet developed by the Global Campaign for Microbicides and updated by
AIDS United and, subsequently, The Well Project was used for this purpose. ${ }^{16}$ Facilitators then asked a set of questions to elicit information about participants' basic awareness and understanding of PrEP, ideas about potential users of PrEP, attitudes about administration and uptake, barriers to and facilitators of use, whether PrEP might affect sexual activity, including condom use, and what kinds of PrEP methods might be desirable (or not). The focus group interview guide was informed by questionnaires used in microbicide and PrEP clinical trials (provided by colleagues in the HIV Prevention Trials Network) and a theoretically-driven interview instrument developed by Kandathil (2010) for a qualitative dissertation study of women's preferences for oral or topical HIV-prevention methods. ${ }^{17}$

\section{Analysis}

All focus group sessions were digitally recorded and transcribed, and transcripts were reviewed and discussed by two researchers to identify predominant themes and any demographic or site differences. The two researchers compared their thematic notes, and incorporated oral comments and notes from the project coordinator, who attended all focus group sessions. This project builds on and uses similar methods to an earlier focus group project supported by AIDS United and conducted by the lead author and others in Oakland, Memphis, San Diego, and Washington, DC in late $2011 .^{18}$ The goal of the focus groups reported here was to determine if the landscape had changed in the year since oral PrEP was approved for women (as well as men) in the US.

\section{Results}

A total of 154 women participated in focus groups. Because the audio recording of one session in New Orleans was indecipherable, data are not included from that focus group or its members. We present data from the 144 women who participated in the other 11 groups. Demographic characteristics of focus group participants are shown in Table 1. Overall, 92\% of participants were black/African American; nearly one-third were 18-30 years old; $53 \%$ were single, divorced or separated; $52 \%$ were employed; $40 \%$ had an annual income under $\$ 10,000$ and $47 \%$ had incomes of $\$ 10,000$ to $\$ 40,000$; and $77 \%$ were stably housed. Sixty percent of the women said they had ever had an HIV test. Only $3.5 \%$ reported having multiple sex partners.

Given the nature of focus groups, no comments from the transcripts are attributed to any individual woman; and we present some back-and-forth among participants (and the moderator) to illustrate how understanding and meaning (including discord) were constructed and conveyed among the participants.

Key findings from this study are that women: (1) were dismayed - in fact many were angry - that they had not heard about PrEP prior to the focus group discussion; (2) had mostly good relationships with their primary care doctors and OB-GYNs and expressed willingness to turn to them for PrEP information and services; (3) had distinct ideas about how PrEP might affect their sex life, including the use of condoms; and (4) supported a range of PrEP delivery options, including pills, gels, injectables, and vaginal rings. There were no significant differences in responses across sites, although members of the research team who attended all focus 
Table 1. Demographic Characteristics of Focus Group Participants $(N=144)$

\begin{tabular}{|c|c|}
\hline Variable & $N(\%)^{\mathrm{a}}$ \\
\hline \multicolumn{2}{|l|}{ Race } \\
\hline Black/African-American & $132(91.7)$ \\
\hline Latina/Hispanic & $10(6.9)$ \\
\hline Other & $2(1.4)$ \\
\hline \multicolumn{2}{|l|}{ Age } \\
\hline $18-30$ & $41(28.5)$ \\
\hline $31-50$ & $72(50.0)$ \\
\hline $51-60$ & $31(21.5)$ \\
\hline \multicolumn{2}{|l|}{ Education } \\
\hline$<\mathrm{HS}$ & $26(18.1)$ \\
\hline HS/GED & $75(52.1)$ \\
\hline Some college or higher & $43(29.9)$ \\
\hline \multicolumn{2}{|l|}{ Employment status } \\
\hline Employed & $76(52.8)$ \\
\hline Unemployed & $68(47.2)$ \\
\hline \multicolumn{2}{|l|}{ Annual Income } \\
\hline$<\$ 10,000$ & $58(40.3)$ \\
\hline$\$ 10,000-40,000$ & $67(46.5)$ \\
\hline$\geq \$ 41,000$ & $14(9.7)$ \\
\hline Missing/no response & $5(3.5)$ \\
\hline \multicolumn{2}{|l|}{ Housing status } \\
\hline Stable & $111(77.1)$ \\
\hline Unstably housed or homeless & $31(21.5)$ \\
\hline Missing/no response & $2(1.4)$ \\
\hline \multicolumn{2}{|l|}{ Relationship status } \\
\hline Single & $62(43.1)$ \\
\hline Married/cohabitating/long-term relationship & $61(42.4)$ \\
\hline Multiple partners & $5(3.5)$ \\
\hline Divorced or separated & $14(9.7)$ \\
\hline Missing/no response & $2(1.4)$ \\
\hline \multicolumn{2}{|l|}{ HIV testing history } \\
\hline Ever tested & $86(59.7)$ \\
\hline Never tested & $56(38.9)$ \\
\hline Missing/no response & $2(1.4)$ \\
\hline
\end{tabular}

${ }^{\text {a}}$ Percentages may not add up to 100 due to rounding.

groups observed that women in the East (Chicago, Newark, New York) and South (Atlanta, Dallas, New Orleans) differed in their thoughts about who were the best sources of information on PrEP: women in the East said doctors and community agencies, while those in the South mentioned friends. Only a few women had ever heard of PrEP before the focus group experience.

These findings, as well as other facilitators and barriers to PrEP uptake identified by participants, are detailed in the following sections.

\section{Knowledge of PrEP}

Almost none of the participants across sites had ever heard of PrEP before the focus group session. By a show of hands, less than $10 \%$ of the sample-only 10 women ( 3 in Dallas and 7 in Atlanta) — had heard about it. Once educated about PrEP, including the fact that oral Truvada for PrEP had been approved by the FDA a year earlier, many participants expressed feeling upset, frustrated, and even angry that they had not learned of it before. Women who had heard of PrEP knew about its use in men, but did not know it was available for women. Similarly, one participant expressed concern that organizations that could potentially disseminate information to women were not receiving funds to do so.

\section{It's frustrating because, yes, the MSM population has a whole bunch of HIV and it's [the HIV epidemic] composed of black women. We're getting it [HIV] because we're not educated about it because people are not educating us. It's that orga- nizations that are trying to educate us can't get the funds or the things that they need to educate us. That's sad to me. It really is. (Dallas)}

Participants were concerned that others in their communities were equally unaware of PrEP, and highlighted the importance of getting information out and of women advocating for themselves. There was discussion across all sites that lack of dissemination of information was influenced by societal devaluation of black women. Some felt that they had not been told about PrEP because people "don't care about black people getting HIV" (Atlanta), a sentiment shared by many black women in the US ${ }^{19}$ :

\section{Because I feel like HIV is killing a lot of black people and they don't mind it happening. They're not going to tell us stuff, that there are other things to prevent it. They are just not telling us about it. I will help campaign. (Atlanta)}

Participants across sites named specific groups, such as sex workers, drug-using women, young women, black women, and women in serodiscordant couples, for whom PrEP ought to be available, demonstrating knowledge about who is most at risk for HIV infection in the US. At the same time, participants in all groups said that PrEP should be available to all women who are sexually active, both to protect their lives and because "you don't know what your man is doing."

I'm thinking if you are in a relationship, a heterosexual relationship, and you aren't sure about your partner, it will be wise because people don't tell the truth about their status. You may think you know your partner but you may not. (Atlanta)

Many participants, but not all, said that they would take PrEP themselves. Women who said they were unwilling to take PrEP said that the addition of pills to existing prevention strategies that they employed was too much:

I say I wouldn't, personally, because you're still going to need a condom for the other STDs beside the pregnancy. It would seem like it's more of a hassle to take the pills, feel the side effects than just when I have sex. (Atlanta)

\section{Sources of information and services}

As can been seen in Table 2, participants identified a number of trusted sources and venues for providing PrEP information and services to women, including clinics, doctors, magazines, billboard ads, social media, schools, and peers-particularly those who were HIV-positive and had experience with antiretroviral treatment.

Notwithstanding the fact that most women had not heard about PrEP from their health care providers, across sites, many participants expressed having strong relationships with their primary care doctors and OB-GYNs and seeing them both as a source of information about PrEP and the best person to deliver PrEP to women. Many women described a long-standing relationship with a primary care doctor who they trusted to provide quality information: 
Table 2. Information Sources for Facilitating PrEP Uptake Among Women

Information source Example quotes

Primary care physician, OB-GYN

CBOs, family planning clinics, and community health centers

Media

Schools

Peer-to-peer,

Friend-to-friend, Outreach
"Your doctor knows you and your body needs personally, so your doctor will know, inform you probably better than anyone of them could because each individual has different needs." (Newark)

"In my opinion, in other words, some of us didn't know those words that we do know now, and we want to know when we came here. I mean, you have to start somewhere. We're here, so maybe we could bring it up to the doctor, you know, what is this? Gynecologist or whatever doctor, primary care doctor, but I think before we even go there, we just have to go to a workshop, learn like we're doing now. That way, we will know what to say when we do approach the doctor." (Atlanta)

Participant 1: "We need more [name of $\mathrm{CBO}$ ] centers in place. We need the funding to have more [name of $\mathrm{CBO}$ ] centers because if you go to any cities you don't have a lot of women-centered prevention organizations."

Participant 2: "I like that. Because we are talking about women, the best place to get information and to make a decision would be going to a woman-centered environment, so I like that." (Dallas)

"My question is I want to know which doctor because I go to my OB/GYN a lot for the female issues. So the regular doctors, they'd be acting a little slow. I want to know, will I be talking to my OB/GYN more about this medication? We want that because the regular doctor, they'd be like, you know, 'well, you just talk to your OB about it.' I'd like to go to the public health [clinic]...I like going to them because they deal with this type of stuff. Some of these doctors, they act like they don't even know." (Chicago)

"I was going to say mass media, social media should be like a gateway to everything. When they came out with the Plan B being over the counter, first thing they did was post it on Facebook." (Atlanta)

Participant 1: "But then, people that have been taking PrEP, they can also - if they get a group of people that took it and wanted to videotape it and show it like a commercial. If they took it and it's okay, like a commercial for something, somebody can see it. It's like she's talking about it and she's showing how it affects and how she feels."

Participant 2: "A day-to-day kind of, that would be a good idea to have a video on her dayto-day." (Chicago)

"They talk about sex in the school, they can talk about PrEP at the same time they talk about sex with children. They should talk about PrEP. PrEP is going to help them make the decision which way they want to go." (New York)

“Just the effects of it, like what happens after they've taken it or any symptoms they've had or what they had to do to prevent or the cost if they don't have any illnesses involved with their - just how they are able to manage with that." (Newark)

“Also, like you said, like how long they've been taking it because you could have taken it yesterday and then come today to tell me that I should take it. I mean that's a good idea, but you still can't give me so much information. It would be nice if you took it last year and you're telling me how you're still maintaining your lifestyle and I can get information from that." (Newark)
I just wouldn't feel comfortable just going to any provider thinking that they're going to give me the correct information that I need. (Dallas)

I will go to my primary care doctor to have my history, know my background and the rest of life, you know, my history. (New York)

At the same time, a number of women did not trust that their doctors were up to speed on PrEP, and were concerned that they (the women) might have to educate these providers, instead of the other way around. One participant said she was willing to initiate a conversation about PrEP with her physician because:

It may just completely slip his mind. It may be something they heard of, but they're not fluent and know everything about it. (Newark)
While the trusting relationship with providers was an advantage to some participants, others expressed concern about revealing personal information to their existing physicians:

I agree with that, but I think also, for me, going to my gynecologist and asking for it would also be like so you're having sex with your husband and you don't trust him. That will be a little bit uncomfortable for me because then even though she and I were good and I talk to her about everything-I have the itch, I have something - I would talk about it. She might ask me, "Well, then why do you need it?" And then I would have to say, "Well, to protect myself." Then it's like, "Protect yourself from what? Is your husband-are you sleeping with someone else?" I think that will kind of bring shame and embarrassment for me so I'm not really sure if I would necessarily ask. I would be a little bit hesitant to ask. (Newark). 
Yeah, I'm thinking like if I told my doctor I had five partners since the last time I saw him, what is my doctor going to think about me, you know? I might tell him about two when I'mreally because I had five. But if she only knew about two, she might say I'm really fine. (Atlanta)

Women-serving organizations, such as the ones at which the focus groups took place, and family planning clinics, such as Planned Parenthood, were also mentioned as the best and most trusted places to receive PrEP information and services. But participants felt that information should be available in all kinds of community health venues. Suggested venues included any group setting where women might congregate, such as social service offices, recovery homes for women, and prisons.

Women highlighted the importance of community peers in getting the word out on PrEP. Some said they specifically wanted to hear from people who had been taking the drug for treatment purposes to have a sense of how it is experienced (e.g., side effects, ease of use, etc.):

I would rather hear from that person that's come in contact with this disease that this medication is supposed to be fighting against instead of hearing from somebody who's just sleeping around or something. (Chicago)

\section{Barriers to PrEP uptake}

A number of potential barriers to PrEP uptake, including concerns about cost and side effects (particularly drug-drug interactions), were identified by the participants, as can be seen in Table 3. Given the predominance of African American women in our sample, it is not surprising that mistrust of the medical establishment was also highlighted as a barrier to

Table 3. Perceived Barriers to Uptake of PrEP Among Women

Barrier Example quotes

Lack of communication among community members

Mistrust of the medical institution

Cost

Side effects

Stigma

Newness of drug

Housing
Participant 1: "Black women, we think to always to be at the end because when the fight is there, we don't want anybody to think that we're at risk, whether it's for cancer, whether it's for - I mean, because a lot of these medications are not tested on black people, on black women. We're always at the end of that and that's because we don't participate in the researches that are coming out. We don't participate in things like this. We don't stand up and say I'm at risk."

Participant 2: “And say, hey, I have that too. I'm at risk too, or, hey, I have that. Yeah, that's what I'm saying." (Dallas)

"I'm like, man, I don't think I can take that medicine because there's so much going on with the world now and how they're doing things with the technology with the fingerprints and all of that. I'm like, man, what if they're trying to put HIV, you know, [in people]? Now you got HIV and the person who didn't have HIV. So I think that will be the biggest problem in the United States when women and when people hear it because they're going to be thinking like, what if they're trying to inject something in me?" (Chicago)

"Income or price. It depends on how much it is or if you have Medicaid insurance (New Orleans).

"The side effects. I would think about it even though it's - I mean, that's like if it would be something to stop me from vomiting but it will give me diarrhea, what side effects will it have on my body? Would it cause any problems to any organs? I don't want to lose a kidney just to stop me from having AIDS. So the side effects." (New Orleans)

"Yes, I would [bring it up to her doctor] because seeing that a lot of medications that you take, it doesn't coincide, okay, say you're a diabetic and your heart, that's why I was asking the risk factor in this, because being a diabetic, there can be other different things that you have. How would this medicine work in coherence with the regular medications that you're on? That's why I brought up the question about the side effects, because there are always side effects with any medication that you take. And that's my main concern, the risk factor in there." (Chicago)

"So if you're around a community of people who don't understand or they don't get it, then you may get the negative look or shunned. So that would kind of stop people from doing it or that would stop people from being open to doing it. But I think if people are widely educated and they understand the complications or the scenarios of what could possibly happen if not, then more people would be open to do it." (Atlanta)

"I would have to say not right now at this early stage. I would like to see a little more testing done and we could see a little more results done before I take the medication. "I don't want to be a guinea pig. That's what I'm saying. I don't want to be a guinea pig." (Chicago)

"However, there are some people who don't have stable housing and they're moving from place to place, people who live in shelters, who live a life where they would be coming home with HIV and AIDS. That would be a hindrance for those people." (New York) 
PrEP uptake, based on historical experiences, such as the Tuskegee syphilis study.

Like with this Tuskegee syphilis thing issue, we think we're getting one thing, right? Well, really they're injecting our brothers, our fathers, and husbands with syphilis. And then down the line, 25-30 years, I just don't trust the whole [thing]. (New Orleans)

Interestingly, few, if any women directly asked about the cost of PrEP. Rather, they focused on the need for it to be covered under their health insurance schemes, whether Medicaid or private insurance, stating that PrEP would be a feasible option if insurance covered it. Many felt that the cost of PrEP ought to be covered by the government, given the nature of the HIV epidemic in the US. The ability to pay for PrEP should be similar to other prevention tools available to women:

Just like the morning [after] pill. If I can go to the hospital and say, look, I had sex last night, I need the morning [after] pill.

I'm getting ready to have sex, can I have PrEP or a vaccination for the PrEP because I'm getting ready to be sexually active? (New York)

Stigma about HIV and antiretroviral medications also was mentioned in most groups as a barrier to PrEP uptake among women. Participants felt that stigma, including internalized stigma, could operate as a deterrent to women even perceiving themselves as being at risk of HIV infection; and it might introduce fear in a woman of her male partner's reaction to her drug-taking, including misperceiving that she was HIV-infected.

It's the same medication for HIV. Many people will judge you, and, oh, why are you taking HIV medication? Maybe because you are HIV positive or maybe people would go-whatever, get upset with you or something like that. (New York)

\section{Other issues and considerations}

Efficacy level. During the focus group discussions, participants were asked what level of PrEP efficacy would be required for them to be inclined to take it. (Participants were told about the efficacy levels for PrEP obtained in clinical studies to date, ranging from the $42 \%$ risk reduction originally observed in $\mathrm{iPrEX}^{6}$ to the over $70 \%$ risk reduction observed in Partners PrEP. ${ }^{7}$ ) Although most women said they would ideally want to see $99 \%$ efficacy, many said they would find $50 \%$ sufficient either because any amount of protection was better than nothing, or because they saw PrEP as ancillary to, not a substitute for, condom use, and believed the additional protection would be helpful.

I'll argue that while it's not 100 percent fool proof and it's not going to save you from everything, you're still going to use it. You're still going to try to do what you can do to keep yourself safe. So I think it's good that they have it. I think if it's accessible, then you can get your hands on it. If it's affordable or covered by your Medicaid or prescriptions that you would take it knowing it's not 100 percent because nothing's 100 percent but Advil. (New Orleans)

Adherence. Efficacy (and effectiveness) of PrEP is very much affected by adherence. Participants were informed about the low PrEP adherence levels observed in clinical trials to date, especially in the international studies among women, and were asked what they thought might have contributed to this. Some thought that the incentives provided in trials might cause women to participate even if they do not intend to take the pill. Others suggested that the women in clinical trials may not have considered themselves to be at risk.

That and you just say, yeah, I've taken the pill. It was good. Where the paperwork is, just because you can't check to see if I did or not. So I'm just going to say I did and get what you've given me for and I'm done. So sometimes it's the compensation. Most of the time we are people-pleasers. We want you to be happy. Like the teacher says study for a test and you come in and say, yeah, I've studied but then you flunked it. (Dallas)

I think that's the key in taking this because you know these women signed up to do this PrEP, but how many of them do you really feel that they thought they were at risk for HIV? I mean, honestly. And they were not taking it because they really didn't feel like they were at risk, but they knew it was something down the line, so I'm not really going to take this because I don't really need it but I want what they're trying to give me at the end of the road. (Dallas)

In general, participants thought it would be hard for most people to take a pill consistently every day. Some attributed this to a "lack of responsibility." Other participants emphasized that the details of daily life get in the way of remembering to take one's medication. They mentioned that women "have a lot on their plates" and their lives are not routine, so it is not easy to remember to take a pill at a regular time.

Moreover, some participants recognized that women at risk of HIV also are likely to be experiencing other challenges, such as depression and low self-esteem, and noted that psychosocial support may be needed along with PrEP to facilitate adherence to it.

Taking medication, sometimes you get depressed with low selfesteem. Women that are at risk basically are either depressed or have low self-esteem... So you need a program along with PrEP just like you have a program for the women, other people, other men who are dealing with the disease, HIV. They have a program to keep their self-esteem going. You definitely need some help with the self-esteem. (New York).

Impact of PrEP on sex life and condom use. Participants were asked about whether PrEP might affect a woman's sex life. Some participants did offer that PrEP might lead to more sex without condoms; others thought PrEP might improve people's sex lives by making them less worried about contracting HIV. As noted above, most participants across sites believed that PrEP should be used as a corollary to, and not a substitute for condom use, because they were keenly aware that PrEP was not going to protect women from STIs other than HIV. But they also recognized the attraction of PrEP for relieving anxiety when the choice to not use condoms is made:

So the thing is, she's going to say, you know, my risk is lower so let's go. That's who we are. It's like you want to feel, you want to really feel your husband or your significant other...with just been condomed, lubed and all that, you ain't really feeling the meat. So you want the meat and you don't take it off. What iffor one time? But that one time will turn into another time, and then another time will turn into another time. She can say, well, we can do it now because the risk is lower so I'm going to do it this time. (Dallas) 
Participant: I would want to today decide about that question. I was going to say that too. Like in my situation, I have a husband so I'm telling my husband. For me, I would think that it would probably be more enjoyable because you think that every time you had unprotected sex, it's like you'll never know that can be your last time, being HIV negative. Just knowing that you have something, you're taking medicine to not get it, it's like sex tends to be more -

Participant: Enjoyable thing.

Participant: It would be consciously in your head like, oh, I know for sure, no matter what he's doing, I know what I'm doing. And I know I'm protecting myself from the virus. (Newark)

Participants also mentioned that the potential side effects of PrEP could have an impact on one's sex life.

I will have to see how it will affect my body, too, because I don't want to take anything that's going to make me not want to have sex and then my boyfriend will question like, wait, why don't you want to have sex with me, who are you having sex with or something or anything to that point? (Newark)

PrEP and pregnancy. Participants recognized the potential of PrEP to allow women whose male partners were HIV-infected to conceive children without the fear that either the woman or the child would become infected-a strategy that currently is being referred to as "PrEPception.",20

PrEP and HIV testing. Participants were asked if they thought that the existence of PrEP would encourage more women to get an HIV test. Responses were mixed, with some participants believing that knowing there was an HIV prevention option available would prompt more women to test, and others thinking it would not be sufficient to combat the fear and stigma that impede HIV testing.

I'd say they are taking it just for the simple fact that if you know they have a pill-I could just speak for me-if I know that they've got a pill that's successful, then I'm going to go get my HIV test to make sure I'm negative. Once I realize I'm negative, hell, give me all the PrEP pills you can give me. (New Orleans)

Delivery methods. Focus group participants were informed by the facilitator that although only oral PrEP had been approved by the FDA, other delivery methods were currently under study, including vaginal rings and injectables. When asked what form of PrEP they would prefer, a number of women said the pill, many said the injectable (some referring to it as "vaccination"), depending on how frequently it would have to be administered, and a few said the vaginal ring, although this appeared to be the least popular option, chiefly based on negative perceptions about the contraceptive NuvaRing.

I will either want an injection like every month or every two months or something. But another problem is like the NuvaRing. I'm never going to do that. I'm not putting that in my vagina, but I would have this mindset like I want to protect myself, and I know I'm going to protect myself so I don't have to go through it because I don't like it. Because some people really just don't like certain things, so you have to give them options. I will never put a NuvaRing in me because I have a fear of me putting it in wrong and me getting hurt. (Newark)
Across sites, having different options for different women's preferences was important to the participants.

So I think that different strokes for different folks, but I think the pill will be something good. But a lot of people who are very secretive, as you know, whatever is done in the dark will come to light. The secretive people would want the shot. They feel like I can just go in here and get this shot. No one is going to know I got it. So that's where that will come in. But if we want to start opening up that conversation and opening up people's minds to PrEP, to HIV prevention period, then it shouldn't even matter what the [formulation or method of delivery is]. (Dallas)

\section{Discussion}

This project is the first to examine knowledge and attitudes about PrEP among a large sample of adult women at elevated risk of HIV infection at multiple sites in the US, and to do so outside the context of clinical trials and after oral Truvada was approved for PrEP use. Its findings are similar to those of the earlier study by Auerbach et al., ${ }^{18}$ also among adult US women, and of Smith et al. ${ }^{13}$ among young, African American, urban adults (male and female). Our results suggest that US women view PrEP as an important HIV prevention option for themselves and their communities, and that they would consider taking it if the cost is covered, side effects are minimal, the efficacy of the drug is reasonable, and PrEP is delivered by trusted providers in trusted venues. Women are concerned that they have not been hearing about PrEP even though it had been approved for use for over a year before the focus groups occurred. Since the participants viewed their doctors as a trusted source of information, they are concerned that their medical providers are equally unaware of PrEP and its application for women. Studies of PrEP among gay and other men who have sex with men (MSM) show similar findings with respect to a lack of knowledge and poor dissemination of information, ${ }^{21}$ and the role of cost and efficacy in facilitating or impeding PrEP uptake ${ }^{22,23}$ Focus group data reported at the 2014 International AIDS Conference suggested that, unlike the women in our study, African-American MSM support the availability of PrEP for other men, but are less willing to take it themselves. ${ }^{24}$

Overwhelmingly, participants in our focus groups believed that PrEP offered hope to women (and others) at risk of HIV, as neatly summarized by a woman at the end of one of the New York sessions when participants were asked if there was anything else they'd like to add:

Nothing other than I hope that it does come out, and I hope that they do allow people to have that chance to stay here and have a second chance at life and just be able to-really just for us to be able to have a chance and just for us to stay here and say, you know what? There are other options, and we can take a pill to prevent ourselves from getting HIV just because the risk is so high. You look at all the statistics in the Bronx and in Brooklyn and Manhattan, there are so many people infected. I think that it's about time that they came up with something like that for us people to have a better choice of life because in reality, I was waiting for someone to come out with a cure of HIV or cure of AIDS. It may not be a cure, but it's some type of-how to prevent it, right. (New York)

\section{Limitations}

This was a community participatory project, and deference was given to the sites to determine the recruitment strategies 
that worked best for them. As a result, our overall sample may have disproportionately included women who seek out HIV, STI, other health and social services and who may be more familiar with HIV prevention. Another limitation was that the sample was overwhelmingly (91\%) black/African American. While black/African American women comprise a majority of HIV cases in the US, Latinas and other racial/ethnic women (including white women) are also affected, and it would have been helpful to have them better represented in the focus groups. However, the fact that women were recruited from a range of sites using a range of venues and methods increases the generalizability of our findings. A third limitation lies with the nature of focus group discussions, during which individuals talk over each other as in normal group conversation. Although the facilitators attempted to control this as much as possible, the recordings and transcripts include many indecipherable passages. While some rich comments may have been lost as a result of this, we think we were able to capture the core points and themes that arose in each focus group and cut across all sessions.

\section{Future directions}

The fact that women in our study expressed strong interest in PrEP underscores the findings in an analysis by Mera and colleagues that women represented the largest group for whom PrEP had been prescribed since FDA approval in 2011. ${ }^{25}$ While most attention to PrEP in the US has been focused on gay and other men who have sex with men-who do still carry the greatest burden of HIV infection in the country-it is clear that women at elevated risk of HIV also are an important population to include in demonstration projects and other efforts to roll-out and scale up PrEP, because when they hear about it, they express wanting to know more and being angry that they did not know about it already. Much like their experience with contraception, women hope to see different options for PrEP administration (oral, vaginal, injectable) that they might use at different times of their lives and in different relationship contexts. Having a mix of methods could facilitate uptake, and increase availability and accessibility. Thus, continued product development research is needed, as is qualitative research to ensure any new PrEP products are desirable and will be used.

There are also important implications for health care providers based on these focus group results. For example, while participants first named women-serving CBOs as places that should be informing women about PrEP, and they were concerned that their primary care providers knew little about PrEP, they ultimately agreed that all healthcare settings and providers need to be responsible for supplying information about PrEP. Surveys of providers reveal significant gaps between providers' PrEP prescribing practices and perceptions about the efficacy of PrEP in preventing HIV transmission and the extant literature demonstrating PrEP's utility as a prevention tool. ${ }^{26-28}$ Therefore, dissemination of PrEP to women at risk of HIV acquisition will necessarily entail efforts to educate providers and address their concerns about prescribing.

There was significant discussion and concern about potential side effects and drug interactions, as well as a concern about being "guinea pigs" for a recently approved drug. Thus, there is certainly an opportunity for providers to clarify that Truvada is not a new drug-only newly approved for PrEP — and to share information about Truvada's history as a generally well-tolerated HIV medication. Uptake of PrEP could also be facilitated by creating and maintaining a trusting relationship between provider and patient. For example, women expressed skepticism about having enough time to have conversations with the physicians about the possibility of PrEP. They also shared potential reluctance to be fully honest with providers about their true risk, which might protect a woman from embarrassment or shame, but limits the provider's ability to truly assess her risk and appropriateness for PrEP. ${ }^{29}$ The focus group discussions suggest that PrEP affords an opening for providers and patients to improve their communications not just about HIV prevention, but sexual health more generally.

The importance of getting information about any new HIV prevention strategy, including PrEP, out to the people who need it most could not be better stated than in this following exchange from a focus group in Dallas:

\begin{abstract}
Facilitator: Is there anything else that you would like to add to this?

Participant: Just end the epidemic. I mean, it just hurts my heart when I think about it.

Participant: Don't be afraid to ask.

Participant: Yes, don't be afraid to ask and go get tested because I'm just tired of seeing our ladies dying.

Participant: Be a support person for somebody. What I mean by being a support person, listen, pay attention to their needs, and don't be so negative.

Participant: Ignorance. I was one that was ignorant about it because I didn't know. Nobody came to us or explained to us what HIV and AIDS were so I was ignorant to a lot of stuff, about how the transmission and this and that, the 'don't touch me.' But once you are equipped and educated about AIDS and about HIV, you're more susceptible to go talk about it and open about it and not afraid to say or be that support for somebody. It's just helping one another. Let's just be there for each other.
\end{abstract}

\section{Acknowledgments}

This project was supported by funds from Gilead Sciences, Inc. (Vignetta Charles, PhD).

The authors would like to thank all the women who participated in the focus groups, the facilitators who led the groups, and the CBOs that helped recruit participants and host the focus group sessions. We appreciate their time, effort, and thoughtfulness in making this a truly communitycollaborative project.

\section{Author Disclosure Statement}

The authors have no conflicts of interest to report.

\section{References}

1. Centers for Disease Control and Prevention: Monitoring Selected National HIV Prevention and Care Objectives by Using HIV Surveillance Data-United States and 6 Dependent Areas-2011. HIV Surveillance Supplemental Report 2013, 18.

2. Centers for Disease Control and Prevention: Diagnosed HIV Infection among Adults and Adolescents in Metropolitan Statistical Areas-United States and Puerto Rico, 2011. HIV Surveillance Supplemental Report 2014, 18. 
3. Centers for Disease Control and Prevention: Diagnoses of HIV Infection in the United States and Dependent Areas, 2011. HIV Surveillance Report 2013, 23.

4. Centers for Disease Control and Prevention: Estimated HIV incidence in the United States, 2007-2010. HIV Surveillance Supplemental Report 2012, 17.

5. Women and HIV/AIDS in the United States. From http:// kff.org/hivaids/fact-sheet/women-and-hivaids-in-the-unitedstates/ (Last accessed September 30, 2014).

6. Grant RM, Lama JR, Anderson PL, et al. Preexposure chemoprophylaxis for HIV prevention in men who have sex with men. N Engl J Med 2010;363:2587-2599.

7. Baeten JM, Donnell D, Ndase P, et al. Antiretroviral prophylaxis for HIV prevention in heterosexual men and women. N Engl J Med 2012;367:399-410.

8. Thigpen MC, Kebaabetswe PM, Paxton LA, et al. Antiretroviral preexposure prophylaxis for heterosexual HIV transmission in Botswana. N Engl J Med 2012;367:423-434.

9. Marrazzo J, Ramjee G, Nair G, et al. Pre-exposure prophylaxis for HIV in women: Daily oral tenofovir, oral tenofovir/emtricitabine, or vaginal tenofovir gel in the VOICE Study (MTN 003). In 20th Conference on Retroviruses and Opportunistic infections. Atlanta, GA. 2013: Abstract 26LB.

10. Van Damme L, Corneli A, Ahmed K, et al. Preexposure prophylaxis for HIV infection among African women. N Engl J Med 2012;367:411-422.

11. Food and Drug Administration (FDA): FDA approves first drug for reducing the risk of sexually acquired HIV infection. Washington, DC, 2012.

12. Preexposure Prophylaxis for the Prevention of HIV Infection in the United States-2014 Clinical Practice Guideline. US Public Health Service, 2014.

13. Smith DK, Toledo L, Smith DJ, Adams MA, Rothenberg R. Attitudes and program preferences of African-American urban young adults about pre-exposure prophylaxis (PrEP). AIDS Educ Prev 2012;24:408-421.

14. Bryman A. Social Research Methods. Oxford University Press, 2012.

15. Sobo EJ. Culture and Meaning in Health Services Research: A Practical Field Guide. Left Coast Press, 2009.

16. PrEP for Women. From http://www.thewellproject.org/hivinformation/prep-women (Last accessed September 30, 2014).

17. Kandathil SM. Women Initiatied Solutions for HIV Prevention (WISH Study): Factors Associated with Intentions to Use Microbicides and Tenofovir. Dissertation. Oregon State University, 2010.

18. Auerbach JD, Banyan A, Riordan M. Will and Should Women in the US Use PrEP? Findings from a Focus Group Study of At-risk HIV-negative Women in Oakland, Memphis, San Diego, and Washington, DC. In XIX International AIDS Conference. Washington, DC, 2012: Abstract FRLBD04.

19. Mackenzie S. Structural Intimacies: Sexual Stories in the Black AIDS Epidemic. New Brunswick, NJ: Rutgers University Press, 2013.
20. US Women and PrEP Working Group: Webinar Series No. 2: PrEP-Ception. From http://www.thewellproject.org/hivinformation/prep-women (Last accessed September 30, 2014).

21. Young I, McDaid L. How acceptable are antiretrovirals for the prevention of sexually transmitted HIV? A review of research on the acceptability of oral pre-exposure prophylaxis and treatment as prevention. AIDS Behav 2014; 18:195-216.

22. Mimiaga MJ, Case P, Johnson CV, Safren SA, Mayer KH. Preexposure antiretroviral prophylaxis attitudes in high-risk Boston area men who report having sex with men: Limited knowledge and experience but potential for increased utilization after education. J Acquir Immune Defic Syndr 2009;50:77-83.

23. Golub SA, Kowalczyk W, Weinberger CL, Parsons JT. Preexposure prophylaxis and predicted condom use among high-risk men who have sex with men. J Acquir Immune Defic Syndr 2010;54:548-555.

24. Philbin M, Parker R, Wilson P, et al. How black men who have sex with men in New York City understand, talk about, and experience pre-exposure prophylaxis (PrEP). In International AIDS Conference. Melbourne, Australia, 2014: Abstract MOPE293.

25. Mera R, Rawlings M, Pechonkina A, Rooney J, Peschel T, Cheng A, Gilead Sciences Inc. Status of Truvada (TVD) for HIV Pre-Exposure Prophylaxis (PrEP) in the United States: An Early Drug Utilization Analysis. In 53rd ICAAC. Denver, CO, 2013: Abstract H-663a.

26. Tellalian D, Maznavi K, Bredeek UF, Hardy WD. Preexposure prophylaxis (PrEP) for HIV infection: Results of a survey of HIV healthcare providers evaluating their knowledge, attitudes, and prescribing practices. AIDS Patient Care STDS 2013;27:553-559.

27. Karris MY, Beekmann SE, Mehta SR, Anderson CM, Polgreen PM. Are we prepped for preexposure prophylaxis (PrEP)? Provider opinions on the real-world use of PrEP in the United States and Canada. Clin Infect Dis 2014; 58:704-712.

28. Krakower D, Ware N, Mitty JA, Maloney K, Mayer KH. HIV providers' perceived barriers and facilitators to implementing pre-exposure prophylaxis in care settings: A qualitative study. AIDS Behav 2014;18:1712-1721.

29. Aaron E, Cohan D. Preexposure prophylaxis for the prevention of HIV transmission to women. AIDS 2013;27: F1-F5.

Address correspondence to: Dr. Judith Auerbach

University of California San Francisco UCSF Mailcode 0886

550 16th Street, 3rd Floor San Francisco, CA 94158-2549

E-mail: judith.auerbach@ucsf.edu 